\title{
Electronic government in public institutions of the department of La Guajira-Colombia
}

\author{
Luis Orcasitas $^{\#}$, Raul J. Martelo ${ }^{* 1}$, Diofanor Acevedo $\$ 2$

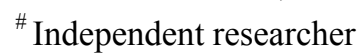 \\ ${ }^{*}$ Faculty of Engineering, INGESINFO research group, University of Cartagena, Colombia. \\ ${ }^{1}$ rmartelog1@unicartagena.edu.co \\ ${ }^{\$}$ Faculty of Engineering, Faculty of Economics Sciences, University of Cartagena, Colombia. \\ 2diofanor3000@gmail.com
}

\begin{abstract}
The objective of this research was to analyze the application of electronic government in public institutions of the Department of La Guajira - Colombia. It was typified as a descriptive field investigation with a population of seventy-five users assigned to the public institutions of the department of Guajira Colombia. The results show, among other aspects, that a large percentage of people do not use ICT, are apathetic or do not have access to communication through the use of electronic means. This and other results allow us to conclude that there is a medium compliance for the electronic Government variable, for which it is necessary to reinforce the perception of the same in public institutions.
\end{abstract}

Keyword - ICTs, Digital Divide, Organizational Structure, Internet, Government Institutions

\section{INTRODUCTION}

Knowing how to anticipate changes and their consequences in the medium and long term is a key aspect for the development of a country [1]. In this way, it is possible to identify the opportunities and challenges presented by the future, stimulating the creation of opportunities based on technology, in order to promote innovation and put it at the service of society [2]. In this sense, the new Information and Communication Technologies (ICT) have evolved exponentially in recent years, due to their interconnection capacity through the Internet, allowing for great innovations [3]. An example of this is the E-government, which through the use of these technologies by the State, allow improving the services and information offered to citizens, increase the efficiency and effectiveness of public management and substantially increase the transparency of the public sector and citizen participation [4].

E-government is perceived as a process of improving governance through greater efficiency, greater citizen participation and improvement of the information infrastructure, including the new challenges of coordination, administration and control of the State's computer resources, and overcoming the digital divide [5]. The usefulness of this type of government has been reflected at the local, regional and national levels. As an example, in [6] it was shown that e-government websites with a high level of usability are considered to have greater credibility, and vice versa, and that there are undoubtedly spaces to improve these aspects in the current websites of electronic government. Also, in [7] the use of an electronic government in Turkey was evaluated, [8] they evaluated a model for the adoption of electronic government. In a similar way, the case is observed in local governments such as the one studied by [9], where the use of social networks such as Facebook and Twitter to access the different services provided by the government was examined.

Therefore, it can be said that the main role of electronic government is: Establish structures and processes that ensure that ICTs are aligned with government strategies, that risks and opportunities are properly managed and that investment in ICT has positive returns [10]. However, the public management of several countries faces adverse circumstances in the implementation of electronic government. Circumstances, such as the time required to implement it, the adoption of multiple models because the reality of each government are different, little budget allocated in terms of technology and finally, the completion of procedures in public entities, does not streamline procedures to the citizens. In this regard, it has been projected from some ministries, the provision of virtual public services to citizens, who are forced to adapt to the use of electronic government.

Consequently, this situation generates an impact to the user due to the fact that in some cases, it lacks response or fails to satisfy its need for attention. In the case of the Government of the Department of La Guajira, it is observed that despite attempts to adapt to the use and incorporation of Information and Communication Technologies, there are flaws that generate complaints from users who require the services of said institutions. Taking into account the above, the objective of this research was to make an updated diagnosis to know in detail, how the concept of electronic government is applied in the public institutions of the Department of La Guajira Colombia, in order to expose the weaknesses that present, so that the various bureaucratic and informative processes that the region carries out can be improved. 


\section{Methodology}

The present investigation was of quantitative non-experimental cross-sectional type. Quantitative, because the variables of nominal or ordinary type were studied [11]; non-experimental, because the data were not manipulated by the researchers [12]; and Cross-sectional, because the data was collected at a certain time [13]. As for the study population, it was made up of 220,610 inhabitants of the urban area of Riohacha and to calculate the sample, the researcher's formula [14] was applied for finite populations. As a result, a sample of 75 inhabitants was obtained.

\section{A. Techniques and research instruments}

For the data collection, the survey was used as a technique and as a tool a closed question questionnaire of Likert type, with the five options of answers: Strongly agree (SA), Agree (A), Undecided (U), Disagree (D) and Strongly Disagree (SD). Where was asked about the dimensions and indicators of the electronic Government variable as shown in Table 1.

TABLE I. Variable Electronic Government with its dimensions and indicators

\begin{tabular}{|c|c|c|}
\hline Variable & Dimension & Indicator \\
\hline \multirow{9}{*}{$\begin{array}{l}\text { Technological } \\
\text { Government }\end{array}$} & \multirow{2}{*}{$\begin{array}{l}\text { Incorporation of Information and } \\
\text { Communication Technologies }\end{array}$} & Internet access and use of online services \\
\hline & & Usefulness of the website \\
\hline & \multirow{2}{*}{ Organizational structure } & Quantity of employees \\
\hline & & Provision of training courses \\
\hline & \multirow{5}{*}{ Digital gap } & Competencies in the use of the computer. \\
\hline & & Internet availability \\
\hline & & $\begin{array}{l}\text { Dissemination about the electronic } \\
\text { government program }\end{array}$ \\
\hline & & Technical aspects - economic \\
\hline & & Socio-cultural aspects \\
\hline
\end{tabular}

For the validity of the instrument, 5 experts were consulted, to whom the first prototype of the instrument was delivered and with the observations made by them, the final questionnaire was validated. For the reliability of the instrument, the use of the Alpha Cronbach coefficient was chosen, for which it was carried out in a pilot test applied to a sample similar to the one in the study, but which was not part of it in order to determine its reliability. As a result, with the Cronbach's alpha coefficient, 0.90 was obtained, indicating a very high level of reliability according to the Scale proposed by [15].

\section{B. Data analysis}

To achieve the objective of the research, a descriptive statistical analysis was performed to visualize the behavior of the data set, grouping them into frequency distributions, tables and graphs that allow the evaluation of the results of the central tendency measures (average), as well as dispersion measures such as the standard deviation and the coefficient of variation. Within it, tables of absolute and relative frequencies are used, with evaluation criteria by indicator, and dimension, according to the variables under study. Likewise, for the analysis and interpretation of the results, the following Scale was designed that is shown in Table 2.

TABLE II. Measurement Scale for the Interpretation of Media

\begin{tabular}{|l|l|l|l|}
\hline Rank & $3,68-5$ & $2,34-3,67$ & $1-2,33$ \\
\hline Category & High Compliance & Medium Compliance & Under Compliance \\
\hline
\end{tabular}

The scale shown in Table 2 was elaborated from the interest of the investigation as far as the values of the ranges as the meaning of the categories, this according to what is expressed by [16] that explains the predominance of the particular character of the research in the elaboration of quantitative measurement criteria, thus exercising the free selection of them for the location of the interpretation categories and their scales.

\section{RESULTS}

The analysis of the instrument applied to the users of the applications of the Public Institutions of the Department of La Guajira - Colombia is then carried out. The analysis was made taking into account the Electronic Government variable, its dimensions: Incorporation of Information and Communication Technologies, Organizational structure and Digital divide with its corresponding indicators. Table 3 shows the results of the dimensions. 
TABLE III. Dimension: Incorporation of Information and Communication Technologies

\begin{tabular}{|c|c|c|c|c|c|c|c|}
\hline \multirow{3}{*}{ Indicators } & \multicolumn{7}{|c|}{ Answers Scale } \\
\hline & SA & $\mathrm{A}$ & $\mathrm{U}$ & $\mathrm{D}$ & SD & \multirow{2}{*}{ Total } & \multirow{2}{*}{ Average } \\
\hline & $\mathrm{RF}$ & $\mathrm{RF}$ & $\mathrm{RF}$ & $\mathrm{RF}$ & $\mathrm{RF}$ & & \\
\hline \multicolumn{8}{|c|}{ Dimension: Incorporation of Information and Communication Technologies } \\
\hline Internet access and use of online services & 25 & 14 & 19 & 18 & 24 & 100 & 3.02 \\
\hline Usefulness of the website & 20 & 16 & 21 & 19 & 25 & 100 & 3.12 \\
\hline Total & 45 & 30 & 40 & 37 & 41 & 200 & 6.14 \\
\hline Average & $\begin{array}{c}22 . \\
5\end{array}$ & 15 & 20 & 18.5 & 24.5 & & \\
\hline Trend & \multicolumn{2}{|c|}{$37.5 \%$} & $20 \%$ & \multicolumn{2}{|c|}{$43 \%$} & & \\
\hline \multicolumn{8}{|c|}{ Dimension: Organizational structure } \\
\hline Quantity of employees & 16 & 15 & 25 & 22 & 22 & 100 & 2.81 \\
\hline Provision of training courses & 23 & 28 & 20 & 17 & 12 & 100 & 3.32 \\
\hline Total & 20 & 22 & 23 & 20 & 17 & 200 & 6.13 \\
\hline Average & $\begin{array}{c}19 . \\
5\end{array}$ & 21.5 & 22.5 & 19.5 & 17 & & \\
\hline Trend & \multicolumn{2}{|c|}{$41 \%$} & $\begin{array}{c}22.5 \\
\%\end{array}$ & \multicolumn{2}{|c|}{$36.5 \%$} & & \\
\hline \multicolumn{8}{|c|}{ Dimension: Digital Gap } \\
\hline Competencies in the use of the computer. & 24 & 28 & 14 & 18 & 17 & 100 & 3.24 \\
\hline Internet availability & 24 & 25 & 18 & 18 & 15 & 100 & 3.25 \\
\hline $\begin{array}{l}\text { Dissemination about the electronic } \\
\text { government program }\end{array}$ & 13 & 16 & 29 & 21 & 21 & 100 & 2.79 \\
\hline Technical aspects - economic & 20 & 23 & 21 & 20 & 17 & 100 & 3.08 \\
\hline Socio-cultural aspects & 21 & 23 & 21 & 18 & 17 & 100 & 3.11 \\
\hline Total & 20 & 23 & 21 & 19 & 17 & 500 & 15.47 \\
\hline Average & 20.4 & 23 & 20.6 & 19 & 17.4 & & \\
\hline Trend & \multicolumn{2}{|c|}{$43.4 \%$} & $20.6 \%$ & \multicolumn{2}{|c|}{$36.4 \%$} & & \\
\hline
\end{tabular}

\section{A. Dimension: Incorporation of Information and Communication Technologies}

The results of this dimension determined that there is a large percentage of people who do not use ICT, are apathetic or do not have access to communication through the use of electronic means. The arithmetic mean of the "Incorporation of Information and Communication Technologies" dimension was 3.07, in contrast with the scale; the average is in the medium compliance category. This is due to the fact that the majority of respondents answered that they make little use of web resources such as pages and applications that facilitate bureaucratic processes for the population. These results indicate that they do not take into account what is stated by [17], who affirms that the use of tics streamlines the management processes that are carried out in a government. However, the use of this tool should be selective according to what is stated by [18], who states that some of these technologies are useful in aspects of governance while others are not useful.

\section{B. Dimension: Organizational structure}

[19] has argued that the organizational structure of public organizations can influence the management of change. In this sense, the arithmetic mean of the dimension was 3.07 in contrast with the scale; its average is in the medium compliance category. The above shows that La Guajira is prepared for the implementation of an electronic government, because there is availability on the part of the government to train people to use technological tools and support electronic government. However, it also shows that there is a lack of employees to attend to the needs of the residents. 


\section{Dimension: Digital Gap}

The breadth of the gap is evident because respondents indicated that they have difficulty accessing a computer and the Internet, and the government does not encourage or speak of the implementation of an electronic government. These results are consistent with what was defined by [20] who affirm that the digital divide is associated with the low level of Internet access, the OECD defines it as "the gap between people, households, companies and geographical areas in the different socioeconomic levels in relation both to their opportunities for access to information and communication technologies (ICT) and to the use of the Internet for a wide variety of activities.

In the case of the general results as an average of the variable, Electronic Government, the following results are obtained: the highest percentage is $21 \%$, corresponding to Totally Agree and Indecisive, then $20 \%$ agree and totally disagree, finally disagree with $19 \%$. The value that was obtained for the arithmetic mean was 3.08 , being located in the scale as medium compliance, therefore, it is necessary to reinforce the perception of the Electronic Government variable in the public institutions under study, which would imply to be in accordance with the definition of the United Nations Organization (UN), in that they are used by the State, to provide services and information to citizens, increase the effectiveness and efficiency of public management, and substantially increase the transparency of the public sector and citizen participation [21].

\section{Conclusion}

The above results allow us to conclude that in the applications of e-Government in the public institutions of La Guajira, Colombia, if Internet access and use of online services are handled externally and internally but with a notable deficit. Regarding the use of the web pages of these public institutions in a moderated way, they provide updated information, offer little ease of use and do not allow to carry out procedures in their entirety through the applications. On the other hand, regarding the organizational structure, there are a small number of employees to attend to the needs of the residents. One of the indicators with the lowest score was Diffusion about the e-government program, for which the improvement of this indicator is recommended, because the necessary instruments must be available to build a more efficient state.

Likewise, the general results of the variable Electronic Government placed it as a medium compliance, indicating the need to reinforce in the public institutions object of study the use of tics so that they can obtain a good management of the variable Electronic Government. On the other hand, it is recommended to design, deepen and comply with efficient strategic guidelines that allow the implementation of Electronic Government as a public policy in the management of the Government of La Guajira.

\section{REFERENCES}

[1] A. Averchenkova, F. Crick, A. Kocornik-Mina, H. Leck and S. Surminski, "Multinational corporations and climate adaptation-Are we asking the right questions? A review of current knowledge and a new research perspective," Grantham Research Institute on Climate Change and the Environment Working Paper, vol. 183, 2015.

[2] OECD, Organisation for Economic Co-operation and Development. Innovation for Development, 2012. Retrieved from https://www.oecd.org/innovation/inno/50586251.pdf

[3] P.C. Verhoef, A.T. Stephen, P.K. Kannan, X. Luo, V. Abhishek, M. Andrews and M.M. Hu, "Consumer connectivity in a complex, technology-enabled, and mobile-oriented world with smart products," Journal of Interactive Marketing, vol. 40, pp. 1-8, 2017.

[4] N. Helbig, J.R. Gil-García and E. Ferro, "Understanding the complexity of electronic government: Implications from the digital divide literature," Government Information Quarterly, vol. 26, no. 1, pp. 89-97, 2009.

[5] J.W. Seifert and E. Petersen, The promise of all things E? Expectations and implications of Electronic Government, In Information Science and Technology Policy Congresional Research Service Library of Congres, 2011.

[6] Z. Huang and M. Benyoucef, "Usability and credibility of e-government websites," Government Information Quarterly, vol. 31, no. 4, pp. 584-595, 2014.

[7] M. Kurfalı, A. Arifoğlu, G. Tokdemir and Y. Paçin, "Adoption of e-government services in Turkey," Computers in Human Behavior, vol. 66, pp. 168-178, 2017.

[8] S.F. Verkijika and L. De Wet, "E-government adoption in sub-Saharan Africa," Electronic Commerce Research and Applications, vol. 30, pp. 83-93, 2018.

[9] X. Gao and J. Lee, "E-government services and social media adoption: Experience of small local governments in Nebraska State," Government Information Quarterly, vol. 34, no. 4, pp. 627-634, 2017.

[10] A. Naser and G. Concha, El gobierno electrónico en la gestión pública. Cepal, 2011.

[11] R. Kumar, Research Methodology. Sage Publications Ltd, 2011.

[12] L. Christensen, R. Burke and L. Turner, Research Methods, Design, and Analysis. Boston, Pearson Education Limited, 2015.

[13] M. Patten and M. Newhart, Understanding research methods. New York, Taylor \& Francis, 2017.

[14] B. Sierra, Ciencias Sociales, Epistemológicas, Lógica y Metodológica, Teoría y Ejercicios. Prentice Hall, 2008.

[15] B.C. Ruíz, Instrumentos de investigación educativa. Procedimientos para su diseño y validación. Venezuela, CIDEG, 2009.

[16] G. Briones, Métodos y técnicas de investigación para las ciencias sociales. Mexico, Editorial Trillas, 2003.

[17] A. Cordella and N. Tempini, "E-government and organizational change: Reappraising the role of ICT and bureaucracy in public service delivery," Government Information Quarterly, vol. 32, no. 3, pp. 279-286, 2015.

[18] F. Bannister and R. Connolly, "ICT, public values and transformative government: A framework and programme for research," Government Information Quarterly, vol. 31, no. 1, pp. 119-128, 2014.

[19] K.R. Isett, S.A. Glied, M.S. Sparer and L.D. Brown, "When change becomes transformation: A case study of change management in Medicaid offices in New York City,” Public Management Review, vol. 15, no. 1, pp. 1-17, 2013. 
[20] A. Kontolaimou, L. Giotopoulos and A. Tsakanikas, "A typology of European countries based on innovation efficiency and technology gaps: The role of early-stage entrepreneurship," Economic Modelling, vol. 52, pp. 477-484. 2016.

[21] ONGEI (Oficina Nacional de Gobierno Electrónico e Informática - ONGEI), Plan Nacional de Gobierno Electrónico, 2014.

\section{AUTHOR PROFILE}

Luis Orcasitas works as independent researcher. Mr. Orcasitas completed his magister from Rafael Belloso Chacin University (Venezuela). Mrs. Orcasitas completed his undergraduate in Civil Engineering at the Corporacion Universitaria de la Costa.

Raúl J. Martelo works as full-time professor at the University of Cartagena (Colombia). Mr. Martelo completed his magister from Industrial University of Santander (Colombia). Mr. Martelo completed his undergraduate in Systems Engineering at the Industrial University of Santander.

Diofanor Acevedo Correa works as full-time professor in the University of Cartagena (Colombia). Dr. Acevedo completed his doctorate from University of Valle (Cali-Colombia). Mr. Acevedo completed his undergraduate in Food Engineering and Pharmaceutical Chemistry at the University of Cartagena. 